\title{
La administración sirve con objetividad los intereses generales: unas pinceladas heterodoxas desde la perspectiva procesal
}

\author{
Juan Manuel Alegre Ávila \\ Catedrático de Derecho Administrativo de la Universidad de Cantabria. Exletrado del Tribunal \\ Constitucional \\ juan.alegre@unican.es
}

\begin{abstract}
Resumen El texto aborda, sin pretensión alguna de exhaustividad, una serie de cuestiones de carácter procesal a través de las que, a modo de contrapunto, pretende aquilatarse el alcance del postulado que sintetiza la posición constitucional y legal de la Administración pública, a saber, el del servicio con objetividad de los intereses generales. Una serie de cuestiones que, aceptadas más o menos acríticamente por la communis opinio, doctrinal y jurisprudencial, revelan flecos que ya modulan el entendimiento ortodoxo del principio de personalidad jurídica de la Administración, ya inciden en el derecho de tutela judicial efectiva. Asíocurre, en primer lugar, con la legitimación para interponer el recurso contencioso-administrativo, respecto de la que diversas normas (contratación, Registro Civil, entidades locales) han operado una extensión que rompe la básica prohibición de que los órganos o los miembros de éstos puedan deducir la oportuna impugnación ante el orden jurisdiccional contencioso-administrativo. $Y$, en segundo lugar, la consagración, en el texto de la Ley de la Jurisdicción Contencioso-Administrativa y en la jurisprudencia, de una serie de figuras o instituciones (justicia cautelar; principio de congruencia; la prueba acordada de oficio por el órgano judicial; el desistimiento y el allanamiento, el reconocimiento extraprocesal y la transacción procesal, como modos anormales o extraordinarios de terminación del procedimiento contenciosoadministrativo) ponen a prueba el principio de igualdad de armas en el proceso y, aun, el mismo sentido del proceso contencioso-administrativo como instrumento de realización de la justicia administrativa.
\end{abstract}

Palabras clave Administración pública; intereses generales; justicia cautelar; congruencia; prueba; desistimiento; allanamiento; reconocimiento extraprocesal; transacción procesal.

\section{The principle of objetive Service to the general interest in doctrine}

\begin{abstract}
The text, without pretending to be exhaustive, addresses a series of questions of a procedural nature through which, as a counterbalance, it attempts to assay the scope of the postulate which synthesises the constitutional and legal position of the public Administration, namely, serving the general interest with objectivity. A series of questions which, more or less uncritically accepted by common, doctrinal and jurisprudential opinion, bring to light points which already temper the orthodox understanding of the principle of legal personality of the Administration, and already have an impact on the right of effective protection of the court. This, in the first place, is the case with the legal standing to apply for judicial review, regarding which different laws (procurement, Civil Register, local councils) have provided an extension which breaks the basic prohibition on their bodies or members to file the pertinent appeal in the contentious-administrative jurisdiction; and, in second place, with the enshrinement, in the text of the Law on the Contentious-Administrative Jurisdiction and in jurisprudence, of a series of arrangements or institutions (precautionary justice; the principle of congruence; evidence agreed on the court's own motion; abandonment and acceptance of the claim, extra-procedural recognition and procedural settlement, as abnormal or extraordinary methods of putting an end to the judicial review) put into question the principle of equality of arms in the proceedings and, even, the actual purpose of the judicial review as an instrument for achieving administrative justice.
\end{abstract}

Key words

Public administration; general interest; precautionary justice; congruence; evidence; abandonment; acceptance of the claim; extra-procedural recognition; procedural settlement. 


\section{I) PRELIMINAR: ADMINISTRACIÓN PÚBLICA Y OBJETIVIDAD. LAS POTESTADES ADMINISTRATIVAS COMO EXPRESIÓN DE LA DIMENSIÓN FINALISTA DE LA ACTIVIDAD ADMINISTRATIVA}

1. La cabecera de estas páginas es el texto de la primera de las proposiciones del artículo 103.1 de la Constitución y título del estudio de Alejandro Nieto para el libro jubilar del profesor García de Enterría. Su propósito no es otro sino el de servir de continente a unas deshilvanadas reflexiones sobre el principio que articula, constitucional y legalmente, la actuación de las Administraciones públicas, el de objetividad. Un principio, según caracterización no controvertida, que define la sujeción de la Administración a la ley por contraposición a la que es propia del poder judicial, en tanto que árbitro de las controversias cuya resolución en derecho tiene encomendada, a saber, el de imparcialidad.

2. Un principio, el de objetividad, que es consustancial a la configuración de la Administración como organización al servicio de los intereses generales (recte: el cumplimiento de la ley como expresión de la voluntad de la mayoría parlamentaria), como instrumento del Estado (el Estado-ordenamiento, en la jerga de la doctrina constitucionalista) para el cumplimiento de los fines, contingentes, variables, del Estado social y democrático de Derecho. En otros términos, como aparato (ejecutivo, por apelar a la inserción de la Administración en el entramado de los poderes estatales, de acuerdo a la tríada clásica que expresa la teoría de la separación de poderes) que, bajo la dirección (política) del Gobierno (artículos 97 de la Constitución y 3.3 de la Ley 30/1992, de 26 de noviembre, de Régimen Jurídico de las Administraciones Públicas y del Procedimiento Administrativo Común [en adelante, LRJ-PAC]), ostenta una serie de potestades (administrativas), esto es, de poderes-función, según la caracterización comúnmente admitida, de corte finalista, teleológicamente enderezados al servicio de los ciudadanos (artículo 4 de la Ley 6/1997, de 14 de abril, de Organización y Funcionamiento de la Administración General del Estado [en adelante, LOFAGE]).

\section{II) OBJETIVIDAD DE LA ADMINISTRACIÓN PÚBLICA Y AUTOTUTELA: LA POSICIÓN DE LA ADMINISTRACIÓN, DEL JUEZ Y DE LOS PARTICULARES}

1. El de objetividad es el principio rector de la actuación de la Administración pública porque, precisamente, la Administración actúa, entabla relaciones jurídicas en tanto que sujeto de derecho, esto es, en tanto que centro autónomo [hago abstracción, aquí y ahora, de las peculiaridades o modulaciones anudadas a las que han dado en llamarse personificaciones fiduciarias o debilitadas, esto es, a determinados entes de corte institucional o fundacional] de imputación de derechos y obligaciones. Una imputación que, en el caso 
de las personas jurídico-administrativas, dimana del conjunto de potestades y de competencias de que en cada momento son titulares (artículo 2.4 LOFA$G E)$, a saber, de su específica capacidad de obrar, noción que, en este sentido, es un mero correlato de la de personalidad (artículo 3.4 LRJ-PAC), con la que, en definitiva, en el caso de los entes públicos, se identifica. $Y$ una actuación que, tal es el reverso de su caracterización, no puede ser imparcial, pues la Administración no es un árbitro [y abstracción hecha, por segunda vez, de los supuestos en que pueda ejercer, stricto sensu, funciones arbitrales], como el juez, sino una persona jurídica, a la que es inherente la idea o dimensión relacional, siquiera ésta se exprese a partir de esa posición de supremacía o preeminencia formal que se sintetiza, como cifra o compendio, en el atributo de la autotutela.

2. Y un principio, el de objetividad, que, por lo que se lleva dicho, singulariza, asimismo, la posición de la Administración frente a la de los particulares, cuya actuación se desenvuelve en la (hetero)tutela de sus derechos e intereses al servicio, en última instancia, de su libertad, principio y valor definidores de su posición en el seno del Estado.

\section{III) ALGUNAS CONSECUENCIAS DE LA CONFIGURACIÓN DE LA ADMINISTRACIÓN PÚBLICA COMO PERSONA JURÍDICA: CONSIDERACIONES SOBRE LA LEGITIMACIÓN PROCESAL}

1. Las líneas que anteceden pueden, sin particular objeción o controversia, aceptarse como communis opinio en la caracterización de la Administración. Las que siguen, en la línea de lo anunciado, se muestran bajo un cariz diferente, el de una serie de observaciones o apreciaciones, sin pretensión de exhaustividad, ni aun bajo la veste de un primario carácter sistemático, que resalten diversas facetas o aristas de ese fenómeno poliédrico que es la Administración pública.

2. La atribución de personalidad jurídica (única) a la Administración, cuya primera formulación expresa data de la Ley de Régimen Jurídico de la Administración del Estado de 1957, es, como se ha señalado, el artificio técnico que permite dar cuenta del carácter o dimensión relacional de aquélla. La Administración, cada Administración, es así, ad extra, una persona jurídica, que, internamente, ad intra, está integrada por un conjunto de órganos (unipersonales o colegiados), jerárquicamente ordenados y servidos por personas físicas, sus titulares. Órganos (entendida esta expresión en la acepción estricta que proporciona el artículo 5 LOFAGE, por contraposición a la genérica noción de "unidad administrativa" ex artículo 7 LOFAGE) que son los que ejercen las potestades con las que, en el ámbito de sus competencias, el ordenamiento jurídico inviste a una concreta Administración para el servicio de los fines que tiene encomendados. $Y$ competencias cuyo ejercicio, precisa- 
mente, ha de llevarse a cabo por los órganos que las tienen atribuidas como propias (artículo 12.1 LRJ-PAC, sin perjuicio de las modulaciones o variantes que este mismo artículo 12 contempla y los siguientes desarrollan), de suerte que el producto jurídico de aquel ejercicio, el acto administrativo, se imputa a la Administración en tanto que persona jurídica. El binomio persona-órgano explica, pues, el modo de actuación (al menos, la actuación de carácter formalizado, la que se desarrolla a través de un determinado procedimiento administrativo) de la Administración, de donde, como corolario, se desprende que los órganos y los miembros de éstos carezcan de legitimación (activa) para impugnar los actos de la Administración (esto es, los actos dictados por los órganos que tienen atribuida la oportuna competencia para su emanación) de la que forman parte [artículo 20 a) de la Ley de la Jurisdicción Contencioso-Administrativa de 1998 -en adelante, LJCA-].

3. Esta carencia, con carácter general, de legitimación activa va, no obstante, seguida de la oportuna apostilla que hace de aquélla una regla relativa, en la medida en que si "una Ley lo autoriz[a] expresamente", los "órganos" de una Administración o los "miembros de sus órganos colegiados" podrán interponer el correspondiente recurso contencioso-administrativo contra la actividad de dicha Administración.

A) Así ocurre con "los miembros de las corporaciones que hubieran votado en contra" de los "actos y acuerdos de las entidades locales que incurran en infracción del ordenamiento jurídico" [artículo 63.1 b) de la Ley 7/1985, de 2 de abril, de Bases de Régimen Local -en adelante, LBRL-]

B) Del mismo modo, y en el ámbito específico de la contratación pública, el artículo inmediatamente anterior al antes reseñado de la LJCA, el 19, contiene un apartado, el 4, que legitima a las Administraciones públicas para interponer recurso contencioso-administrativo "contra las decisiones adoptadas por los órganos administrativos a los que corresponde resolver los recursos especiales y las reclamaciones en materia de contratación a que se refiere la legislación de Contratos del Sector Público sin necesidad [...] de declaración de lesividad". Un recurso especial y unos órganos a los que, respectivamente, se refieren los artículos 310 y 311 de la Ley 30/2007, de 30 de octubre, de Contratos del Sector Públicos, artículos añadidos por el artículo 1.3 de la Ley 34/2010, de 5 de agosto.

4. La Ley 20/2011, de 21 de julio, de Registro Civil legitima a la Dirección General de los Registros y del Notariado, órgano del Ministerio de Justicia, para “impugnar ante el Juzgado de Primera Instancia competente las decisiones adoptadas por los Encargados de las Oficinas [del Registro Civil] por ser las mismas contrarias a la doctrina establecida por el Centro Directivo. En estos 84 procesos serán emplazados los interesados". Una impugnación, pues, ante 
el orden jurisdiccional civil que se llevará a cabo de conformidad a lo dispuesto en el artículo 781 bis de la Ley de Enjuiciamiento Civil, precepto introducido por la Disposición final Cuarta. Tres de la referida Ley 20/2011.

\section{IV) OBJETIVIDAD DE LA ADMINISTRACIÓN PÚBLICA Y LEGITIMACIÓN PROCESAL: LA DEFENSA DE LA LEGALIDAD EN LOS ÁMBITOS CONTRACTUAL Y DEL REGISTRO CIVIL}

1. Estos supuestos de legitimación, sin perjuicio de la peculiaridad que reviste el del artículo 63.1 b) LBRL [y que, expresado incidentalmente, puede, de alguna manera, decirse teleológicamente inspirado en el artículo 162.1 a) de la Constitución, que legitima a una fracción del Congreso de los Diputados y del Senado -cincuenta diputados, cincuenta senadores- para interponer el recurso de inconstitucionalidad contra las leyes de las Cortes Generales, además de contra las dictadas por los Parlamentos o Asambleas Legislativas de las Comunidades Autónomas], ofrecen una, tal es la tesis que ahora se esboza, peculiar conexión con el principio de objetividad. Si éste es consustancial a la actividad, al funcionamiento de la Administración, en la dimensión aquí considerada, de carácter impugnatorio o reactivo, el principio de objetividad pasa, en los ámbitos expuestos, por el tamiz de la verificación judicial (ya contencioso-administrativa ya civil) de la corrección, en un caso, de la decisión adoptada por un órgano específicamente diseñado para velar, mediante la resolución de un recurso administrativo ad hoc, por la salvaguarda de la libre concurrencia en el acceso a la contratación pública; y, en el otro, de las decisiones de los encargados de la oficinas del Registro Civil cuando a aquéllas se imputa la contravención de la doctrina de la Dirección General de los Registros y del Notariado.

2. Una impugnación o reacción judicial que, obsérvese, se efectúa sin la, con carácter general, preceptiva declaración del carácter lesivo de la decisión administrativa que pretende llevarse ante la jurisdicción contencioso-administrativa (artículos 103.1 LRJ-PAC y 19.2, 43 y 45.4 LJCA). Declaración que, si presupuesto de la impugnación contencioso-administrativa, es, sin embargo, improcedente de formularse la oportuna pretensión ante el orden jurisdiccional civil, siquiera sea porque, a lo que se me alcanza, el artículo 87.3 de la Ley de Registro Civil de 2011 constituye una rigurosa novedad en nuestro panorama legislativo, al consagrar, en línea del establecimiento del referido orden como el competente para conocer de las pertinentes oposiciones o impugnaciones frente a los actos dictados por los órganos del Registro Civil (las oficinas del Registro Civil y la Dirección General de los Registros y del Notariado), con la excepción de los supuestos de adquisición de la nacionalidad española por residencia ex artículos 87.1 de la Ley de 2011 y 781 bis.1 de la Ley de Enjuiciamiento Civil, según la redacción introducida por la Disposición final Cuarta.tres de aquélla, al consagrar, decía, la legitimación de la Direc- 
ción General de los Registros y del Notariado para impugnar las decisiones de los encargados de las oficinas del Registro Civil.

\section{v) LA ADMINISTRACIÓN PÚBLICA ANTE LA JURISDICCIÓN CONTENCIOSO- ADMINISTRATIVA: ALGUNOS EXTREMOS QUE PONEN EN CUESTIÓN EL PRINCIPIO DE IGUALDAD PROCESAL, EN PARTICULAR, EL FUMUS BONI IURIS, LA CONGRUENCIA, LA PRUEBA Y LOS MODOS, DIFERENTES DE LA SENTENCIA, DE FINALIZACIÓN DEL RECURSO CONTENCIOSO- ADMINISTRATIVO}

1. Administración Pública-Derecho Administrativo-Jurisdicción ContenciosoAdministrativa es la secuencia que, desde la óptica del binomio autotutelacontrol, conforma la arquitectura de esta rama del ordenamiento jurídico que regula la organización y la actuación de estos sujetos peculiares que son las Administraciones públicas. La preeminencia, lógica y conceptual, de la primera de estas realidades (no hay, en efecto Derecho Administrativo sin Administración Pública) debería, en puridad, llevar a preconizar, como hace años postulara Lorenzo Martín-Retortillo, la unidad jurisdiccional para la Administración Pública, esto es, el monopolio del contencioso-administrativo en el control de aquélla, y no sólo, como acaece ya, para con la responsabilidad [artículo 2 e) LJCA 98], orden jurisdiccional ante el que pueden comparecer en calidad de codemandados los particulares. Mas esta unidad jurisdiccional demanda, como es natural, de la oportuna intervención del legislador, superando así una inercia (régimen jurídico-orden jurisdiccional) sin justificación institucional alguna.

Y una inercia, por lo demás, que se resiste a abandonarnos, tal y como en relación con este asunto de la responsabilidad, en general, y, específicamente, respecto del aseguramiento de aquella responsabilidad, manifiestan las recurrentes disputas jurisdiccionales plasmadas en los pronunciamientos de las diversas Salas del Tribunal Supremo, incluida la de Conflictos de Competencia.

2. En todo caso, en el engranaje del contencioso-administrativo pueden identificarse algunas piezas que, en particular por la acogida que se les ha dispensado, gozan de un favor inconveniente (siquiera en el primero de los supuestos que se citan este favor se halle a día de hoy en franco declive) por una razón radical, la que atañe a su propia constitucionalidad.

3. Así ocurre, en primer lugar, con el fumus boni iuris, o apariencia de buen (o, incluso, del mejor) derecho como criterio rector de la justicia cautelar. Una justicia cautelar que, no obstante su predicamento por obra de la imponente figura del profesor García de Enterría, no es sino un vector, y un vector quizá no esencial, del problema de fondo (sin duda, junto con el 
que atañe a la propia ejecución de los pronunciamientos judiciales) que aqueja al contencioso-administrativo, como, en general, a la justicia, la proliferación de asuntos, que ha forzado a colocar el de las medidas cautelares como figura estelar de la justicia administrativa, tal y como revela la ejemplar monografía de Susana de la Sierra, en la que, a la luz de la experiencia comparada, se ofrece como alternativa (harto discutible, por otro lado) a esta justicia cautelar la de una justicia de fondo rápida montada sobre la especialización o diversificación de "contenciosos", no todos ellos de naturaleza jurisdiccional.

A) Pues bien, incorporado el referido criterio, a la doctrina jurisprudencial por obra del Tribunal de Luxemburgo, no sólo no aparece en los artículos 129 y 130 de la Ley de 1998 (diseñados sobre el modelo de la suspensión cautelar del amparo ex artículo 56 de la Ley Orgánica del Tribunal Constitucional de 1979), y cuya aplicación en el orden de referencia en virtud del carácter supletorio de la Ley de Enjuiciamiento Civil es improcedente, pues ninguna aplicación supletoria hay en juego, como en su momento mostrara Roberto Bustillo Bolado, dado el carácter cerrado del sistema que los citados preceptos establecen, sino que su colisión con normas constitucionales que otorgan derechos fundamentales me parece, como intenta razonarse seguidamente, clara.

B) La utilización de dicho criterio no debe prejuzgar el fondo del asunto, se dice. Mas ¿no hay una contradicción, acaso irresoluble, en la propia formulación de esta cautela, desde el momento en que juzgar, siquiera provisionalmente, acerca de la "bondad" de uno de los derechos en presencia -que, de contrario, también puede ser el de la Administración demandada, desde el momento en que, en aplicación del mismo, se deniegue la medida cautelar solicitada- no puede hacerse sino incorporando a aquel juicio una apreciación sobre la "mejor" calidad del derecho tutelado? Y, si esto es así, la preferencia, siquiera cautelar o provisional, de uno de los derechos en presencia, ¿no supone irremediablemente la conculcación de la tutela judicial debida a la otra parte procesal, con desconocimiento, así, de las exigencias del artículo 24.1 de la Constitución, por más que el Tribunal Constitucional -Sentencia 175/2001 y las en su estela situadas- se empeñe en que los derechos fundamentales no deben ponerse al servicio del ejercicio de las potestades administrativas?

C) Empero, con independencia de lo anterior, la cimentación de una mera medida cautelar en un criterio como el de la bondad de uno de los derechos en presencia, ¿no se traduce en un prejuicio en el juzgador, que de este modo ha exteriorizado siquiera con la índole provisional del pronunciamiento reclamado en ese momento procesal, una opinión que, en sentido estricto, forma parte del juicio que únicamente debe verterse en sentencia?, y, por tanto, ¿no es este prejuicio una vulneración de la 
imparcialidad del juzgador, esto es, del derecho a un proceso con todas las garantías de que habla el artículo 24.2 del texto constitucional?

4. En segundo lugar, es sabido que la peculiaridad de la congruencia en el contencioso-administrativo [como el propio Tribunal Constitucional ha señalado: Sentencia 100/2004 -caso: Julio Aparicio, matador de toros-] estriba en que el juzgador ha de pronunciarse en el límite de las pretensiones y de los motivos que articulan la demanda y la oposición a ésta (artículo 33.1 LJCA). Este entendimiento de la congruencia conoce de una insospechada manifestación, rigurosamente ajena a los demás órdenes jurisdiccionales: la habilitación al juzgador para que ponga de manifiesto a las partes la existencia de otros motivos en que basar la demanda y la contestación a la demanda (artículo 33.2 LJCA), y no sólo en el procedimiento en primera o única instancia [artículo 65.2 LJCA: "Cuando el Juez o Tribunal juzgue oportuno que en el acto de la vista o en las conclusiones se traten motivos relevantes para el fallo y distintos de los alegados, lo pondrá en conocimiento de las partes mediante providencia, dándoles plazo de diez días para ser oídas sobre ello. Contra esta providencia no cabrá recurso alguno"], sino, incluso, con ocasión del conocimiento del proceso en grado de apelación [párrafo primero del artículo 85.8 LJCA: "El Secretario judicial acordará la celebración de la vista, en cuyo caso hará el oportuno señalamiento, o la presentación de conclusiones si lo hubieren solicitado todas las partes o si se hubiere practicad prueba. La Sala también podrá acordar que se celebre vista, que señalará el secretario, o que se presenten conclusiones escritas cuando lo estimare necesario, atendida la índole del asunto. Será de aplicación a estos trámites lo dispuesto en los artículos 63 a 65”]. Pues bien, ¿qué juicio debe merecer esta beligerante irrupción del juzgador en el debate procesal suscitado en sus propios términos por las partes?

A) De entrada, y a despecho del carácter subjetivo de la justicia administrativa, ante la que se ventilan estrictamente, como el profesor García de Enterría viene insistiendo desde hace años, pretensiones y no una sedicente depuración de la legalidad, $n$ puede dejar de advertirse un añejo resabio, el viejo "proceso al acto", en el que lo decisivo era, precisamente, verificar el correcto proceder de la Administración, de suerte que la legitimación activa no pasaba de ser una mera exigencia técnica, la individualización de un punto de conexión para acceder al debido, por coherencia del sistema, pronunciamiento dirimente.

B) De ahí que, no obstante la doble cautela introducida por los preceptos citados (puesta de manifiesto de otros motivos en que fundar la demanda y la oposición a ésta; interdicción de prejuzgar el asunto), la cuestionada facultad tenga un sentido procesal bien nítido y definido: reforzar con otros motivos no expuestos en la demanda la pretensión de anulación del acto recurrido. De donde: 
a) Primera quiebra: la debida tutela judicial de las dos partes procesales. El reforzamiento de la posición del recurrente implica una ruptura de armas en el proceso, dimensión inherente al derecho a un proceso con todas las garantías (artículo 24.2 de la Constitución), por más que formalmente se respeto el principio de contradicción (la apertura de un trámite de audiencia) y a su través el derecho de tutela judicial del artículo 24.1 del texto constitucional.

b) Y, segundo reproche: la (obligada en términos formales) expresión de que la puesta de manifiesta de esos otros motivos se hace sin prejuzgar el asunto, no traspasa los muros del mero voluntarismo retórico. Aquella puesta de manifiesto revela la formación en el juzgador de un prejuicio que, una vez más, no puede merecer un juicio favorable desde la perspectiva del derecho que consagra el artículo 24.2 de la Constitución.

5. Más: esta injerencia del juzgador en el debate procesal alcanza al ámbito de la prueba. El artículo 61 LJCA prescribe:

“1. El Juez o Tribunal podrá acordar de oficio el recibimiento a prueba y disponer la práctica de cuantas estime pertinentes para la más acertada decisión del asunto.

2. Finalizado el período de prueba, y hasta que el pleito sea declarado concluso para sentencia, el órgano jurisdiccional podrá también acordar la práctica de cualquier diligencia de prueba que estimare necesaria.

3. Las partes tendrán intervención en las pruebas que se practiquen al amparo de lo previsto en los dos apartados anteriores.

4. Si el Juez o Tribunal hiciere uso de su facultad de acordar de oficio la práctica de una prueba y las partes carecieran de oportunidad para alegar sobre ello en la vista o en el escrito de conclusiones, el Secretario judicial pondrá de manifiesto el resultado de la prueba a las partes, las cuales podrán, en el plazo de cinco días, alegar cuanto estimen conveniente acerca de su alcance e importancia.

5. El Juez podrá acordar de oficio, previa audiencia a las partes, o bien a instancia de las mismas, la extensión de los efectos de las pruebas periciales a los procedimientos conexos. A los efectos de la aplicación de las normas sobre costas procesales en relación al coste de estas pruebas se entenderá que son partes todos los intervinientes en los procesos sobre los cuales se haya acordado la extensión de sus efectos, prorrateándose su coste entre los obligados en dichos procesos al pago de las costas". 
A) Así pues:

- Facultad del juzgador de "acordar de oficio el recibimiento a prueba", así como de "disponer la práctica de cuantas estime pertinentes".

- Facultad, una vez finalizado el período de prueba y hasta que el pleito sea declarado concluso para sentencia, del juzgador de "acordar la práctica de cualquier diligencia de prueba que estimare necesaria”.

- En ambos supuestos, derecho de las partes de intervenir "en las pruebas que se practiquen".

- De haberse acordado de oficio "la práctica de una prueba" y carecer las partes de "oportunidad para alegar sobre ello en la vista o en el escrito de conclusiones", supuesto que concurrirá bien en el segundo de los casos mencionados bien cuando no haya habido vista o conclusiones, las partes podrán "alegar cuanto estimen conveniente acerca de su alcance e importancia" a partir de la puesta "de manifiesto [d]el resultado de la prueba".

- Facultad del juzgador de acordar de oficio, "previa audiencia de las partes", "la extensión de los efectos de las pruebas periciales a los procedimientos conexos”.

B) Lo dicho antes a propósito del principio de congruencia es de pertinente extensión a la injerencia del juzgador en el ámbito de la prueba. La facultad de disponer de oficio el recibimiento del pleito a prueba, la práctica de pruebas o la de cualquier diligencia de prueba rompe el monopolio, ínsito a la misma idea de proceso, de las partes para definir los términos, fácticos y jurídicos, del debate procesal. Una ruptura que, precisamente, lo es de la imparcialidad del juzgador, que, una vez más, en la búsqueda de la "verdad" procesal, aquí, de la depuración de la legalidad administrativa, esto es, de la verificación de la adecuación al ordenamiento jurídico de la actuación administrativa traída a la jurisdicción, interviene, más allá de la prueba solicitada por las partes, en la determinación de los hechos que han de servir de base para dictar el oportuno pronunciamiento, en contravención, así pues, del artículo 24.2 de la Constitución.

6. Si la configuración del debate procesal por las partes y, en consecuencia, la rigurosa abstención al respecto del juzgador es consustancial al proceso y, por ende, inherente al derecho a un proceso con todas las garantías (recte: la imparcialidad del juzgador), la expresión del ejercicio de la función jurisdic- 
cional ha de referirse, en puridad, a la sentencia, esto es, la resolución que con carácter definitivo se pronuncia sobre las pretensiones de las partes. No obstante, el procedimiento puede, asimismo, terminar en virtud del desistimiento del recurrente, el allanamiento del demandado, el reconocimiento por la Administración demandada en vía administrativa de las pretensiones del demandante y la transacción procesal (artículos 74 a 77 LJCA). Una terminación, y esto es lo que interesa destacar en este momento, que, sin embargo, no tiene lugar siempre de manera automática, con los efectos a ello anudados, una vez producidos los actos que definen los referidos modos, pues, en los términos que ahora se dirán, el juzgador puede enervar aquellos efectos mediante el dictado, en su caso, de la correspondiente sentencia.

A) Así, y por lo que se refiere al desistimiento del recurrente, la terminación del procedimiento se declarará si el demandado (amén del Ministerio Fiscal en los supuestos de acción popular) presta su conformidad o no se opone al desistimiento (artículo 74.3), salvo que se aprecie "daño para el interés público", en cuyo caso el Juez o Tribunal resolverá "lo que proceda" (artículo 74.4).

B) En caso de allanamiento del demandado, "el Juez o Tribunal, sin más trámites, dictará sentencia de conformidad con las pretensiones del demandante", salvo que ello suponga "infracción manifiesta del ordenamiento jurídico". En este caso “el órgano jurisdiccional comunicará a las partes los motivos que pudieran oponerse a la estimación de las pretensiones y les oirá por plazo común de diez días, dictando luego la sentencia que estime ajustada a Derecho" (artículo 75.2).

C) El reconocimiento por la Administración demandada en vía administrativa de las pretensiones del demandante comportará que "el Juez o Tribunal [dicte] auto en el que declarará terminado el procedimiento [...] si el reconocimiento no infringiera manifiestamente el ordenamiento jurídico”, en cuyo caso “dictará sentencia ajustada a Derecho” (artículo 76.2).

D) Finalmente, para el caso de que "las partes [lleguen] a un acuerdo que implique la desaparición de la controversia”, "el Juez o Tribunal dictará auto declarando terminado el procedimiento, siempre que lo acordado no fuera manifiestamente contrario al ordenamiento jurídico ni lesivo del interés público o de terceros" (artículo 77.3).

E) El “daño para el interés público", la "infracción manifiesta del ordenamiento jurídico”, el reconocimiento [por la Administración demandada en vía administrativa de las pretensiones del demandante] que "infringiera manifiestamente el ordenamiento jurídico” o el acuerdo procesal "manifiestamente contrario al ordenamiento jurídico [o] lesivo del inte- 
rés público o de terceros", pues, como causas que obstan la producción de los efectos inherentes a estos "otros modos de terminación de terminación", esto es, la disconformidad de dichos efectos con el ordenamiento jurídico, que habilita al juzgador para resolver lo que proceda, esto es, para dictar la sentencia que estime ajustada a derecho. La legalidad, por tanto, como límite al poder de disposición por las partes de las pretensiones hechas valer en el proceso, de suerte que aquéllas no devienen domini de manera incondicionada del proceso puesto en marcha con el recurso contencioso-administrativo y, eventualmente, proseguido en sucesivas instancias o grados procesales.

F) Las consideraciones vertidas con anterioridad a propósito de la congruencia o de la prueba son de pertinente extensión a los límites que los artículos 74 a 77 LJCA establecen en relación al, como se ha dicho, poder de disposición de las partes procesales sobre sus propias pretensiones. Unos límites que, en puridad, son uno solo, la misma legalidad administrativa, que de este modo se erige, de ahí la facultad otorgada al juzgador, en valladar infranqueable del desistimiento, el allanamiento, el reconocimiento en vía administrativa y el acuerdo procesal.

G) Una defensa de la legalidad administrativa que, de manera indubitada, está presente en el caso del desistimiento, no obstante la singular redacción del artículo 74.4. En efecto, el “daño para el interés público" a que este precepto se refiere no puede ser sino la infracción manifiesta del ordenamiento jurídico, dicción empleada por los artículos 75.2, 76.2 y 77.3 para los supuestos del allanamiento, el reconocimiento en vía administrativa y el acuerdo procesal, respectivamente. En otros términos, si el juzgador considera que la actuación impugnada en vía contenciosoadministrativa comporta una infracción del ordenamiento jurídico [¿manifiesta, a fin de mantener la simetría con los supuestos de los artículos 75.2, 76.2 y 77.3?], resolverá en el sentido de declarar la improcedencia del desistimiento ["lo que proceda", según el artículo 74.4], esto es, mediante el dictado de la oportuna "sentencia ajustada a derecho", tal y como, para los casos del allanamiento y el reconocimiento en vía administrativa, previenen los artículos 75.2 y 76.2; o, en sentido contrario, de concluirse que la actuación administrativa llevada ante la jurisdicción es conforme al ordenamiento jurídico, el allanamiento o el reconocimiento en vía administrativa [...contrario, ha de entenderse, al contenido de aquella actuación] decaerán frente a las exigencias de la legalidad administrativa, esto es, el mantenimiento de la actuación impugnada, cuya declaración en tal sentido, por tanto, integrará la oportuna "sentencia ajustada a derecho" (artículos 75.2 y 76.2).

H) El artículo 77.3 LJCA consigna como impeditivo del dictado del auto por el que se declare terminado el procedimiento, en el caso de que "las par- 
tes [llegaren] a un acuerdo que implique la desaparición de la controversia", que lo acordado fuere "manifiestamente contrario al ordenamiento jurídico [o] lesivo del interés público o de terceros". La referencia al "interés público" o al "[interés] de terceros", como motivos eventualmente enervantes de la declaración de terminación del procedimiento, pudiera inducir la individualización de causas distintas, en relación a los supuestos de desistimiento, allanamiento y reconocimiento en vía administrativa, de la mera "infracción del ordenamiento jurídico" como factores determinantes del decaimiento del acuerdo procesal en tanto que modo del terminación del procedimiento contencioso-administrativo. Pueden hacerse, a este propósito, unas sucintas consideraciones.

I) No parece, empero, que el "interés público", a este efecto, sea cosa sustancialmente distinta de la observancia del "ordenamiento jurídico", siquiera sea porque, de aceptarse esta hipótesis, el legislador habría confiado al juzgador la verificación de un canon o parámetro cuya apreciación, prima facie, ha de corresponder, y, además, con un carácter esencialmente discrecional, a la Administración pública. El interés público a que el artículo 77.3 LJCA se refiere no es, no puede ser, sino el respeto del ordenamiento jurídico, de la legalidad administrativa.

J) En esta misma línea, el "interés de terceros" no pasa de ser una mera cláusula de estilo. No es, en efecto, fácilmente pensable un supuesto en el que, en el ámbito del contencioso-administrativo [ocioso parece recordar que el supuesto es sustancialmente diferente de lo que acaece en el ámbito privado, así, ad exemplum, la necesaria aprobación por el juez de un convenio en el marco de un proceso de separación o divorcio, en el que aquél es garante del superior interés de los menores de edad], una controversia entre un recurrente y una Administración pública pueda afectar a terceros que no hayan tenido oportunidad de comparecer como parte en el proceso, terceros respecto de los que, de resultar concernidos por la actuación administrativa impugnada, deviene preceptivo su emplazamiento personal y, en consecuencia, factible su personación a efectos de la propia y directa defensa de sus derechos e intereses.

K) En suma, pues, la legalidad administrativa, el ordenamiento jurídico-administrativo como límite del desistimiento, el allanamiento, el reconocimiento en vía administrativa y el acuerdo procesal, esos "otros modos de terminación del procedimiento" cuyos efectos decaen si el juzgador entiende que su concreto ejercicio se traduce en una "infracción manifiesta del ordenamiento jurídico".

En otros términos, si, como se vio con anterioridad, la configuración del debate procesal por las partes resulta modulada por la injerencia del 
juzgador ya mediante la entrada en juego de otros motivos distintos de los esgrimidos por aquéllas para articular sus pretensiones ya en virtud de la redefinición del material fáctico, aquella injerencia alcanza su expresión máxima en los supuestos en los que la terminación del procedimiento contencioso-administrativa tiene lugar de conformidad a las previsiones de los artículos 74 a 77 LJCA, supuestos en los que puede afirmarse que las partes dejan de ser domini de sus propias pretensiones [recte: de la cabal extensión en el sostenimiento o defensa de aquéllas] de entender el juzgador que, como resultado del ejercicio de aquellas previsiones, se produce una vulneración de la legalidad administrativa, cuya preservación se erige así en canon absoluto del proceso contencioso-administrativo. Una consecuencia que, una vez más, no parece conciliable con la razón de ser del proceso como instrumento de defensa o amparo del específico entendimiento que las partes hacen de sus derechos e intereses y, por extensión, de la misma definición del papel del juzgador.

\section{RESEÑA BIBLIOGRÁFICA}

El artículo de Alejandro Nieto al que se alude en el apartado I.1 es La Administración sirve con objetividad los intereses generales, en Estudios sobre la Constitución española. Homenaje al profesor Eduardo García de Enterría, Civitas, Madrid, 1991, tomo III, $2.185 \mathrm{ss}$.

Sobre la (nueva) configuración del Registro Civil introducida por la Ley 20/2011, de 21 de julio, de Registro Civil, Juan Manuel Alegre Ávila, El nuevo Registro Civil: administrativización y digitalización, en Consejo General del Notariado, Autonomía de la voluntad en el Derecho Privado. Estudios en conmemoración del 150 aniversario de la Ley del Notariado, coordinación de Lorenzo Prats Albentosa, Wolters Kluwer/Consejo General del Notariado, Madrid, 2012, tomo IV (Otras formas de expresión), 585 ss., en particular, por lo que hace al régimen de impugnación, 608 ss.

A propósito de la unidad jurisdiccional para la Administración Pública [apartado V.1], baste la remisión a dos clásicos artículos de Lorenzo Martín-Retortillo Baquer: Responsabilidad patrimonial de la Administración y jurisdicción, "Revista de Administración Pública”, 42, 1963, 169 ss., y Unidad de jurisdicción para la Administración pública, "Revista de Administración pública", 49, 1966, 143 ss. Y, en relación a las disputas jurisdiccionales en el ámbito de la responsabilidad civil extracontractual de la Administración pública, en particular, en lo atinente al aseguramiento de aquella responsabilidad [apartado V.1], Juan Manuel Alegre Ávila, La responsabilidad civil extracontractual de la Administración Pública y la jurisdicción contencioso-administrativa, "Revista Española de Derecho Administrativo", 126, 2005, 191 ss., y en El aseguramiento de la responsabilidad civil extracontractual de la Administración Pública, "Derecho y Salud", volumen 13, número 1, enero-junio 
Una exposición de la jurisprudencia del Tribunal Supremo sobre la ejecución de las sentencias contencioso-administrativas [apartado V.3] en Juan Manuel Alegre Ávila, La jurisprudencia del Tribunal Supremo en materia de ejecución de sentencias contencioso-administrativas, "Revista Española de Derecho Administrativo", 129, 2006, 147 ss. -y en La ejecución de sentencias contencioso-administrativas, coordinación de Ana Sánchez Lamelas, Thomson-Aranzadi, Zizur Menor (Navarra), 2006, 43 ss.-. El asunto de las medidas cautelares [apartado V.3] ha sido tratado, desde una perspectiva de derecho comparado, ejemplarmente por Susana de la Sierra en Tutela Cautelar Contencioso-Administrativa y Derecho Europeo. Un Estudio Normativo y Jurisprudencial, prólogo de Luis Martín Rebollo, Thomson/Aranzadi, Zizur Menor (Navarra), 2004, en particular, 259 ss., por lo que se refiere al criterio del fumus boni iuris. En relación al concreto alcance de la aplicación con carácter supletorio en lo contencioso-administrativo de la Ley de Enjuiciamiento Civil [apartado V.3 A)], Roberto Bustillo Bolado, La Aplicación de la Ley de Enjuiciamiento Civil en el Contencioso-Administrativo, prólogo de Manuel Campos Sánchez-Bordona, Thomson/Aranzadi, Zizur Menor (Navarra), 2005, en particular, 49 ss. páginas en las que se enmarca el sentido de la supletoriedad de la ley procesal civil. Y, por lo que atañe a la titularidad de los derechos fundamentales por los poderes públicos [apartado V.3 B)], me remito a Juan Manuel Alegre Ávila, $A$ vueltas con los derechos fundamentales de los poderes públicos: una nota (A propósito de la STC 175/2001, de 26 de julio), "Revista Vasca de Administración Pública", 61, 2001, 319 ss.

Nota.-Las páginas que anteceden han sido escritas para el homenaje al profesor Santamaría Pastor. 
